Konzil aufgenommen und weitergeführt sah: die geistliche Entdeckung der Kirche, die Liturgische Bewegung und die Bibelbewegung. Er hat sie als Aufbrüche hin zur "Sache" des Glaubens aufgenommen, auf dessen Mitte hin sich alles Bemühen um die Erneuerung der Kirche, um die angemessene Feier der Liturgie und um das Verstehen der Bibel zu öffnen habe. Er hat in diesem Sinn ein Leben lang auf den verschiedenen Ebenen, auf denen er wirkte, Menschen auf diese "Sache" des Evangeliums hinzuführen gesucht. In besonderer Weise hat dabei seine 1953 gefällte Entscheidung, den Lehrstuhl für Exegese des Neuen Testaments am Philosophisch-Theologischen Studium in Erfurt zu übernehmen, sein Leben und Arbeiten auf sehr spezifische Weise geprägt. Er wechselte damals von Münster in die stalinistisch geprägte $\mathrm{DDR}$, in einen Raum also, der seine $\mathrm{Ar}$ beitsbedingungen entscheidend verschlechterte und seine Kontaktmöglichkeiten zunehmend einengte. Er ist freilich so zu einem hilfreichen „Vermittler" geworden, der seine theologischen Verbindungen in die Arbeit in Erfurt einbrachte und zugleich Erfahrungen kirchlicher Existenz im Osten Deutschlands nach außen vermittelte. „Daß uns DDR-Katholiken dieses Land nicht zu einem theologischen Ghetto wurde, sondern trotz allem zu einem Ort vielfältiger Kommunikation mit der theologischen und kirchlichen Entwicklung des damaligen Westens, ist neben vielen anderen auch Heinz Schürmann zu verdanken." (J. Wanke).

Ein besonderes Interesse des Verstorben lag darin, den Austausch unter den Fachkollegen zu fördern: Er stand mit R. Schnackenburg am Anfang der Arbeitsgemeinschaft deutschsprachiger katholischer Neutestamentler. Er initiierte zusammen mit G. Delling das jährlich in Wittenberg abgehaltene Treffen der evangelischen und katholischen Neutestamentler in der DDR. Er suchte schon früh den Kontakt zu den Fachkollegen in den osteuropäischen Ländern und regte das Wiener Colloquium Biblicum mit an, das seit 1980 alle zwei Jahre die österreichischen Exegeten mit den Kollegen aus den östlichen Nachbarländern verbindet. Nicht zufällig war die letzte Ehrung, die ihm gewidmet wurde, die Verdienstmedaille der Päpstlichen Fakultät Krakau, die J. Chmiel ihm am 4. Dezember 1998 in Erfurt überreichte.

Er wurde am 18. Dezember 1999 in Erfurt zu Grabe getragen. Thomas Schmeller sprach für die Fachkollegen Worte ehrenden Gedenkens. RIP.

Erfurt, 22. Februar 2000. Georg Hents ch e l, Claus-Peter März.

\title{
Nachruf auf Helmut Merklein
}

Am 30. September 1999 verstarb der international bekannte und renommierte Bonner Neutestamentler Helmut Merklein. Gerade erst 59-jährig erlag er in seinem Wohnort Wachtberg-Adendorf nahe Bonn einem wenige Monate zuvor ausgebrochenen Krebsleiden.

Geboren wurde Helmut Merklein am 17. September 1940 in Aub/Unterfranken. Nach dem Abitur studierte er von 1959-1964 Theologie an der Philosophisch-Theologischen Hochschule in Bamberg und wurde 1965 zum Priester der Erzdiözese Bamberg geweiht. Nach einer dreijährigen Tätigkeit als Kaplan in Rehau begann er 1968 bei Rudolf Schnackenburg in Würzburg mit einer Dissertation zum Thema "Das kirchliche Amt nach dem Epheserbrief“, die er im Wintersemester 1971/72 abschloß. Unmittelbar darauf wurde er Schnackenburgs Assistent und Habilitand. 1976 legte er seine Habilitationsschrift vor mit dem 
Titel „Die Gottesherrschaft als Handlungsprinzip. Eine Untersuchung zur Ethik Jesu ". Diese Arbeit erlebte ebenso wie die thematisch eng verwandte und in verschiedene Sprachen übersetzte Studie "Jesu Botschaft von der Gottesherrschaft. Eine Skizze" mehrere Auflagen. Person und Wirken Jesu werden in diesen Forschungsbeiträgen konsequent im Kontext frühjüdischer Theologie deuteronomistisch-apokalyptischer Prägung interpretiert. So wird einem anachronistischen, aus der Perspektive späterer christlicher oder rabbinischer Theologie gezeichneten Jesusbild eine Absage erteilt. Helmut Merklein hat hier wissenschaftliche Standardwerke geschaffen, die für die neutestamentliche Exegese und Theologie noch auf lange Zeit wegweisend und befruchtend sein dürften.

Neben der Jesusforschung bildete die Paulusforschung den zweiten Schwerpunkt im Werk Helmut Merkleins. Dies belegen eindrucksvoll die beiden Sammelbände "Studien zu Jesus und Paulus" (1987) und "Studien zu Jesus und Paulus II" "(1998). Im Mittelpunkt seiner Paulusstudien stehen die paulinische Christologie und Soteriologie. Vor allem angeregt durch den Römerbriefkommentar von U. Wilckens und die Arbeiten von B. Janowski zur Konstruktion alttestamentlicher Sühnevorstellungen gelingt es Helmut Merklein aufzuzeigen, daß Paulus seine Kreuzestheologie und Rechtfertigungslehre nicht unter Preisgabe seiner jüdischen Identität entwickelt. Vielmehr integriert Paulus die ihm widerfahrene Offenbarung des Gekreuzigten als Sohn Gottes konsequent in das System seiner theologischen Wurzeln mit den Koordinaten Toragehorsam und gottgewährte Sühne. In den gut zwei Jahrzehnten seines akademischen Forschens und Lehrens seit 1977 begleitete Helmut Merklein das Projekt seines ${ }$ "Kommentars zum 1. Korintherbrief“. Hier rang er im Dienst eines adäquaten Zugangs zur inhaltlich-theologischen Aussageintention des Paulus beharrlich um ein neues Konzept der Vermittlung von textlinguistischen und historisch-kritischen Methoden. Den ersten Band mit der Kommentierung der Kapitel 1-4 legte er 1992 vor. In seinem letzten Lebensjahr arbeitete er, ermöglicht durch ein von der DFG gewährtes und ein reguläres Forschungsfreisemester, mit größter Intensität an der Fertigstellung des Kommentars. Das Manuskript zum zweiten Band (Kapitel 5,1-11,1), dessen Veröffentlichung im Januar 2000 Helmut Merklein nicht mehr erleben sollte, war gerade abgeschlossen, als die Diagnose der Krebserkrankung erfolgte. Trotz der belastenden Chemotherapie arbeitete er mit der ihm eigenen Disziplin und Energie, soweit es sein Körper zuließ, weiter. Mitten in der Kommentierung des dem Thema Auferstehung gewidmeten 15. Kapitels nahm ihm der Tod bei V. 12 den Stift aus der Hand.

Ein herausragendes Merkmal, das Helmut Merklein als Wissenschaftler kennzeichnete, war sein beständiges Streben nach Erweiterung des eigenen Horizonts. Das Neue und Fremde faszinierte ihn, da es ihn zur Auseinandersetzung herausforderte und ihn zwang, die eigenen Positionen immer wieder kritisch zu hinterfragen. So wundert es nicht, daß er sein Interesse vor allem in den letzten Jahren verstärkt der Religionsgeschichte sowie der Archäologie und Topographie des Nahen Ostens zuwandte. Seine besondere Liebe galt Agypten. Sie schlug sich nicht zuletzt nieder in einigen Beiträgen über religionsgeschichtliche Querbezüge zum Neuen Testament, insbesondere im Bereich der Christologie. Ein zweiter Schwerpunkt war Jordanien. Hier arbeitete er bis zuletzt zusammen mit seinem Kollegen und Freund, dem Archäologen Robert Wenning, an dem DFG-

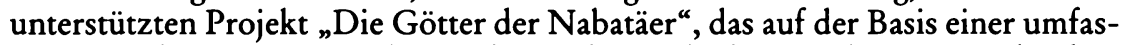
senden Dokumentation und kritischen Sichtung der literarischen, epigraphischen und ikonographischen Quellen eine Rekonstruktion der nabatäischen Religionsgeschichte anstrebt. Den Abschluß dieses Projekts, das einen wichtigen Bau- 
stein im Gesamt der Religionsgeschichte des Vorderen Orients in neutestamentlicher Zeit darstellt, durfte Helmut Merklein ebenfalls nicht mehr erleben.

Das Ansehen, das er als Wissenschaftler genoß, fand seinen Ausdruck in zahlreichen Mitgliedschaften und Engagements. So war er u.a. von 1987-1990 Mitglied im Committee der Studiorum Novi Testamenti Societas, von 1984-1991 Mitglied des Wissenschaftlichen Beirats des Katholischen Bibelwerks Stuttgart und seit 1997 Mitglied der Nordrhein-Westfälischen Akademie der Wissenschaften (Klasse für Geisteswissenschaften). Seit 1991 war er Vorsitzender des Katholischen Bibelwerks. Er fungierte als Mitherausgeber der Stuttgarter Bibelstudien, der Bonner Biblischen Beiträge, der Koblhammer Studienbücher Theologie und des Jabrbuchs für Biblische Theologie sowie als Fachberater für den Bereich Neues Testament bei der Neuauflage des Lexikons für Theologie und Kirche. Seit 1996 war er Schriftleiter der Zeitschrift Welt und Umwelt der Bibel, die auf seine Initiative hin in Orientierung an und in Kooperation mit der französischen Zeitschrift Le Monde de la Bible ins Leben gerufen wurde.

Helmut Merkleins bedeutende Leistungen als Forscher wurden in geradezu idealer Weise ergänzt durch seine Qualitäten als akademischer Lehrer. Es machte ihm Freude, Wissen zu vermitteln, mehr aber noch, zu eigenständigem und kritischem Nachdenken anzuregen. Die exegetischen Methoden waren für ihn kein Selbstzweck, sondern standen im Dienst der theologischen Aussage. Dabei verstand er es meisterhaft, die existentiell bedeutsamen Linien neutestamentlicher bzw. biblischer Theologie in ihren vielen Facetten auszuziehen. Auch in seinen zahlreichen Publikationen kommt diese Fähigkeit immer wieder zum Ausdruck, vielleicht am deutlichsten in der bewußt für einen breiteren Leserkreis konzipierten kleinen Monographie „Die Jesusgeschichte - synoptisch gelesen“.

Wer Helmut Merklein einmal persönlich begegnet ist, mag erahnen, daß seine Kolleginnen und Kollegen, seine Schülerinnen und Schüler und sein Freundeskreis durch seinen Tod weit mehr verloren haben als einen herausragenden Wissenschaftler und akademischen Lehrer. Seine geradezu überquellende Lebensfreude, sein ausgeprägter Mutterwitz und Humor wirkten ansteckend. Seiner offenen, umgänglichen Art, seinem Charme, der im ursprünglichen Sinn des Wortes etwas mit Charisma zu tun hatte, konnte man sich schwer verschließen. Die Wirkung, die er in der direkten Begegnung mit Menschen entfaltete, erwuchs wohl nicht zuletzt aus seiner (bisweilen unbequemen) Geradlinigkeit und aus seiner Authentizität: Theoretische Erkenntnis und praktisches Handeln, Lehren und Leben klafften bei ihm nicht auseinander, sondern bildeten eine Einheit. All dies war getragen von einem tief verwurzelten Glauben, einer unerschütterlichen Hoffnung und einer unverfälschten Liebe zu Gott und den Menschen. Dieses feste Fundament half Helmut Merklein auch, seinen aussichtslosen Kampf gegen die todbringende Krankheit bis zuletzt mit heiterer Gelassenheit und menschlicher Größe zu führen. Am 5. Oktober 1999 wurde er in Ebensfeld/Oberfranken, dem Heimatort seines Vaters, zu Grabe getragen.

Bonn, 10. Februar 2000.

Marlis Gi e le n. 